\title{
THE RESIDENTIAL-ENVIRONMENT CLIMATE SENSE OF PLACE IN LOCATIONS OF URBAN REVITALIZATION
}

\author{
Miriam Billig \\ Bar llan University, Department of Geography, Ramat Gan 52900, Israel \\ e-mail: biligm@mail.biu.ac.il
}

\begin{abstract}
This paper proposes to use the concept of "sense of place" to describe the particular atmosphere prevailing in any specific residential environment. The sense of place is expressed through a number of variables of behavior and variables of personal feeling. The study identifies the sense of place in and around two new housing developments, built in two neglected neighborhoods in the city of Ramat Gan. Results were based on ethnographic analysis of in-depth interviews of residents, half of them living in the new buildings and half of them in adjacent old buildings.
\end{abstract}

Key words: housing developments; sense of place; urban revitalization

\section{INTRODUCTION}

Every residential environment has its own particular atmosphere or sense of place. This paper will describe the characteristics of sense of place in housing developments, and how it could be used to differentiate between them, to relate between physical planning and its sociological impact, and to assist in optimizing the planning of future housing developments. This study is of an initial, exploratory nature and further studies will be required to develop this methodology.

\section{THE RESIDENTIAL ENVIRONMENT}

Using the term residential environment allows us to distinguish between the physical boundaries of the neighborhood as defined by the local authority for the purpose of urban organization (Hallman, 1984), and the boundaries of more limited areas as subjectively perceived by their residents. Churchman \& Rosenfeld (1978) state that the term residential environment refers to the dimensions and boundaries that are significant to the residents themselves and to the social relations and activities they want to conduct there. Rapoport $(1980-81,1997)$ 
claims that since the definition of space is partially based upon physical and social images, the variables of the definition are not only the area and its dimensions but also the degree of overlap between social and physical space. Billig \& Churchman (2003) have found that physical boundaries affect the attitudes and behavior of residents.

In this paper, the term residential environment stands for the physical and social space referred to in the subjective feeling and in the behavior of its residents. This includes any population group or physical environment referred to by residents, whether in favorable or unfavorable terms.

\section{SENSE OF PLACE OF THE RESIDENTIAL ENVIRONMENT}

Jackson $(1994,157-158)$ describes the current use of sense of place as describing the atmosphere to a place, the quality of its environment and possibly its attraction by causing a certain indefinable sense of well-being that makes people wanting to return to that place. Kropf (1996, p. 247) emphasizes the need to put any account of physical characteristics within the context of aspects such as activities and intentions in order to move to a better account of character of the place. Isaacs (2000) has explored the application of sense of place to perception and quality of places and urban design.

Jiven \&Larkman (2003) present a critical historical and theoretical overview of the concept of "sense of place", particularly as applied to urban areas. The use of sense of place in urban contexts predominates in the contemporary professional literature. They argue that it is the people - individuals and society - that integrate the features of topography, natural conditions, symbolic meanings and the built form through their value systems, to form a sense of place. They also propose that designers need to develop more theoretically informed conceptions of sense of place, extensively informed by the views of the people directly involved.

This paper proposes to use "sense of place" to describe the particular atmosphere prevailing in a given residential environment. In residential environments the sense of place is established mainly by the residents themselves and is formed at the inter-subjective level, connecting between the behavior of the individual and that of the other residents. The sense of place of the residential environment will thus be affected by perceptions of its physical characteristics, by the feeling and behavior of its residents, and by the interactions between them.

We assumed the following: a. The sense of place is a multivariate characterization of a particular residential environment, formed by the subjective feelings and patterns of behavior of its residents and resulting from relations between groups of residents, from relations within each group of residents, and from their attitude towards the physical aspects of the residential environment. b. Many social and physical factors will influence the sense of place of the residential environment. c. Each residential environment will be characterized by its own unique sense of place. 


\section{ETHNOGRAPHIC DESCRIPTIONS AS A TOOL}

According to Geertz (1973), any ethnographic description is an interpretation; the subject of interpretation being the "social discourse". Through his ethnographic notes the anthropologist records the social discourse, thereby rendering it from a transient event at a specific moment into a lasting story that can be looked at again and again. In Geertz's opinion, the main objective of interpretational anthropology is not to receive answers to questions but to display the answers given by others, documenting the person's words so that they may be consulted again from time to time.

The uniqueness of anthropological research is that topics the investigator had not necessarily thought of before beginning the study are able to surface in the ethnographic description. These topics may be significant from the point of view of the people participating in the research, and may help the investigator to better understand them.

\section{THE STUDY}

The subject came up in a wider study that examined the interaction between different residential environments and various population groups, wherein people interviewed were asked to describe their residential environment. Their residential environments had undergone significant changes due to new housing developments built within old neighborhoods. From the point of view of the original residents, the changes that have occurred were mainly in the neighborhood population, in infrastructure and services and in the appearance of the environment as seen from their window. From the point of view of the new residents the change was their moving to an entirely new residential environment.

One of the results of such environmental changes is that people have to redefine and resituate their social boundaries. Their comparison between "then and now" and between "us and them" focuses on these issues, and enables a better definition (for themselves and for the researcher) of the way different residents perceived their residential environment before the change and afterwards, as well as of their feelings towards the other population with whom they have contacts since the change has occurred.

This paper deals with two out of five new housing developments built in neglected neighborhoods in the city of Ramat Gan, Israel. Results are based on ethnographic analysis of in-depth interviews conducted with 80 women in their homes in the environment of the housing developments, about half of them living in the new housing developments and half of them in the adjacent old buildings. Each woman was asked to describe the residential environment as she saw it. No guidelines were given as to what areas or aspects to describe. Thus the topics they addressed were spontaneously chosen, according to their importance to the women interviewed. Our research also described the physical characteristics of each of the housing projects, the available public services, and the characteristics of the population in each of the residential environments. 
From the ethnographic descriptions we identified the variables that in our opinion, encompass the sense of place of the residential environment. For lack of space we present only a number of examples showing how these variables were derived from the wording of those interviewed.

\section{RESULTS}

Residential environment and population of the Sapir housing development: The Sapir housing development was built on the main street of what was once regarded as a distressed neighborhood. In the 1990's a process began, whereby buildings unfit for living were demolished and the Sapir new housing development built in their place. It consists of five buildings five to six stories high, with altogether 94 apartments. Apartments are relatively large, three to four bedrooms, with a penthouse on top of each building. Each building has a courtyard and a fence that separates it from adjacent buildings.

The women interviewed in the new buildings were relatively young, sixty eight percent were below 40. Eighty-two percent of the households consisted of three to five people; $32 \%$ of them had children aged two to four. Their ethnic origin was heterogeneous. $68 \%$ had more than 12 years of education, $41 \%$ of these 16 years or more. Around $70 \%$ of the women were employed.

Across the street are nine old two-story buildings built in the 1950's, with 49 apartments altogether. Most apartments have one bedroom, some apartments have been enlarged to up to 3 bedrooms. Walking along the street, one sees well-maintained new buildings along with severely neglected buildings.

The women interviewed in the old buildings were older: $39 \%$ were aged 41 to 60 , $28 \%$ were aged 61 to 90 . Twenty-two percent of those lived one or two persons per apartment, and $56 \%$ three to seven persons. Ninety-four percent of their families originated from Islamic countries in Asia or Africa, mainly from Iraq; 40\% were born in Israel. Fiftysix percent of those interviewed had 11 years of education or less, and $22 \%$ had 12 years or more. Around $51 \%$ of the women were employed.

Study of the sense of place in the Sapir housing development: We examined the ethnographic descriptions from the Sapir housing development, of which the following are typical examples: A new resident describes the differences between "new" and "long time residents: "Our population is a usual one, 20\% intellectuals judging from their appearance. When you cross the street, what do you see...delinquents, very simple people”. Long time residents mentioned the differences between themselves and the new residents as follows: “ Those Ashkenaziml' shouldn't be looking down on us and shouldn't forget we have been living here for a long time...they are snobs, nothing is good enough for them, so let them go away", or: "A barrier exists between Ashkenazim and Orientals. We see the

\footnotetext{
${ }^{1}$ Referring to the ethnic European background of the new population in the new buildings.

2 The translation of the term used in Hebrew for people from Islamic-country backgrounds.
} 
type of relations existing with the other population by their negative attitude towards the "others" that creates tension between them.

We learned about differences in life style, as described by a new resident: "You find here a behavior you are not used to see in reasonable places. I am shocked the way they are dressed... people out on the street in slippers or men sitting outside without shirts... drug addicts with their arms full of needle marks, or a 12 year old boy with a beer can at noon, or shouting on the street, family quarrels being fought outside". The atmosphere is affected by pronounced differences between population groups with regard to norms and life styles. For example, lack of concern for a particular type of privacy among the long time population causes feelings of aversion to that population.

Differences were also found in attitudes towards the disadvantaged, as described by women living in the old buildings: "We have a lone person... not 100 percent well in his mind...every morning neighbors ask him whether he needs anything... a neighbor brings him some soup"... or: "a family with a difficult mental condition...the father and one girl are hospitalized in the psychiatric ward...we are like family to them" or: "he has nobody to take care of him, the poor guy, he screams, throws with things...we buy things for him in the grocery store. We learned that long time residents are tolerant towards disadvantaged neighbors and help them.

The feeling of belonging of the long time population is not necessarily towards the entire neighborhood: "In some parts of the neighborhood I have no reason to be there, the more distant streets. I feel I belong only to my own street, actually only to the old side of the street". Or: "I don't know what's going on in the middle of the neighborhood, I know what's going on in my own street... my street is quiet, I don't know those new buildings, only the old two story buildings". Another woman said: "I have never lived in any other neighborhood, I was born here... the residents have changed, they don't belong here, they are from outside. I've got nothing to do with anyone of them. We are in touch with my husband's family who live around here... that's enough". We learn that the feeling of belonging of those interviewed is limited to a certain section of the street where they live, and includes the old buildings only.

References to differences between "the new" and "the old" physical environment were emphasized by a long time resident: "The street looks funny, a 50 year old building with graffiti on it saying "welcome to hell" and next to it a gorgeous new building...I open the window and see all that green of theirs... They look (out of the window) and see all the rubbish and the solar water heaters (on the old buildings)". Also new residents said: "On our side they have put nice new lamp posts and paved a new sidewalk. On the other side they haven't done anything, the old lamp posts are still there, the broken up sidewalk...it's not nice, why draw such a line between people? Those interviewed expressed feelings of enjoying the new well looked-after buildings, while expressing feelings of aversion to the old neglected buildings.

The new population avoids using the local schools and public services, as described by women from the new buildings: "Residents of the new buildings don't send their children to the neighborhood schools and kindergartens...I don't want my children to learn 
together with that population. I also won't send them to the community center...The health care clinic is right next to us, but the doctors are only good for a backward population, not for me". By not using the neighborhood's public services, new residents also diminished the chances of meeting each other, as described by a resident of the new buildings: "Between the new residents there aren't many contacts. You find some relations among people living in your building, but I have no idea who is living in the new building next to us, and I miss that. Everyone sends his children to a different school, because they don't want to send them to the neighborhood school". Avoiding the use of local educational and public facilities results from their desire to avoid meeting or having any relations with the other population group. This however, also limits their opportunities to meet with people of their own population group.

Residential environment and population of the Yahalom housing development: The Yahalom housing development was built on an open space bordering on an old neighborhood built in the 1950 's. In the 1990's new residents began to move into the prestigious Yahalom housing development.

The Yahalom housing development was built in a star shaped layout with a garden in its middle. It is surrounded by parking space for the residents and by a two-meter high wall facing the old part of the neighborhood. The wall does not totally enclose the area but creates a clearly sensed separation between the new and the old buildings. The development consists of five 7 to 13 -story buildings with 30 to 52 relatively large three to four bedroom apartments in each. Separate educational facilities and a small commercial center were built for the use of residents of the development.

Nine old two-story buildings adjacent to the development, with altogether 36 apartments were also included in the study. Some of the apartments have been enlarged by residents of the younger generation. The long time population has its public services in the old neighborhood, including commercial centers, schools and playgrounds.

In the Yahalom housing development, the women interviewed were mostly middle aged, $60 \%$ between 41 and $60,30 \%$ between 31 and 40 . Families were mostly well settled. Sixty percent were families of four or more. Their ethnic origin was heterogeneous; $50 \%$ of them were born in Israel. All had 12 years of education or more, of these $41 \%$ had 16 years or more. About $70 \%$ of the women were employed.

In the adjacent old buildings, $40 \%$ of the women interviewed were aged 60 to 90 , only $20 \%$ were aged 20 to 30 . Many were lone elderly people and old couples, but there were also young families with two to three children, and some families with many children. Ninety percent originated from Islamic countries, $40 \%$ of those were born in Israel. Older women generally had a lower level of education. Younger and middle aged ones had 12 years of education or more. Generally, younger women were employed and older women were mostly housewives.

Study of the sense of place in the Yahalom housing development: We examined the ethnographic descriptions from the Yahalom housing development, of which the following are typical examples. "People in the new buildings are white collar workers, they don't start their cars before seven in the morning, they go to the office. I see the people of the old 
neighborhood, they are all of low class, aged, many lone people sitting on their balcony or hanging around the place". From the descriptions we clearly see the differences in life style between the two population groups, and little regard for the long time population by the new population.

Long time residents compared themselves with the new population: "We are simpler, normal people. I can start a conversation with any stranger, but they won't start a conversation. For instance, if somebody knocks on the door and asks for a glass of water, I'd be glad to help him. I will even offer him something to eat. They might give him a glass of water but would be suspicious, they wouldn't like it". Or: "I'm not afraid to walk alone outside at night because I know all the neighbors and they know me". We learned about their tolerance for the disadvantaged and strangers, and a feeling of security in public space.

We learned about social and family ties among the long time population from women in the old buildings: "The people here are very community minded... everybody knows everything about everybody, it's a nuisance because there is no privacy, but on the other hand it's good because you are not alone". "The whole neighborhood is more like a home... we help each other and care about each other... there are strong ties between the families within an extended family. Sometimes five brothers of the same extended family live in the neighborhood, together with their parents as well as their married children. The whole neighborhood is like a family, when anything happens to anybody, everybody comes and helps, you are not alone... "When I come home from work and I want to rest, my neighbor will immediately offer to take the kids, and she will also bake a cake for me if necessary. You won't find this in the new buildings, there everyone is on his own". The sense of place in the old neighborhood is one of good relations between neighbors, the feeling of a community and family ties among the same population. There is however, a noticeable lack of a more reserved type of privacy.

To women from the new housing development privacy is very important "Everyone here lives on his own, there is no desire to mix with each other, people don't bother each other. The layout of the housing development provides a lot of privacy. You won't hear what your neighbor is doing at home, when he flushes the toilet or opens the water tap, I like this very much... there is a lot of privacy here, nobody will enter your home without first phoning you, even your next door neighbor". There is a strong emphasis on the importance of privacy among the new population.

Their emphasis on privacy does not prevent social relations among residents of the new housing development: "The building is pretty much socially integrated, not all but most people are. Relations are close on the same floor, but also between people on different floors. People don't meet every day except for jogging together in the park, people from the entire building do so together every evening... the layout of the development is like a closed neighborhood, and that causes people to know each other, relatively speaking”. We learned about good relations among the same population in the housing development.

The location of buildings and their physical design strongly affected the residents' perception of the residential environment, as described by a resident from the new housing 
development: "The wall that separates us from the nearby neighborhood is important because it gives us a feeling of security...the wall creates a sort of feeling of belonging, something in common between the residents of the housing development". Or: "The fact that we have a number of tall buildings with a garden in their middle creates something in common among the various residents, it's like paradise for parents and children, a closed area with a school and kindergarten at walking distance without the problem of crossing roads. Schools of high standard with a lot of parent involvement add to the feeling of communality. Many people here are of similar age, education and life style, my children have friends in all the buildings so they can go and see each other on their own, or play together in the public garden". We learned about good relations among the same population. The wall adds to a feeling of belonging to the similar buildings, and provides a feeling of security in public space. There is also satisfaction with the physical environment.

In the adjacent old neighborhood, the sense of place is different. A student temporarily living in that neighborhood describes the residential environment: "People here are very noisy, there is a noisiness originating from the family character of the neighborhood. There is no distinction between inside the house and outside, a child cries and the mother shouts at him from the window, neighbors living across the street communicate by shouting from their balcony". We learned about norms and life style in public space, on close ties between neighbors of the same population, and on a different conception of privacy.

Variables for Evaluating the Sense of Place of a Residential Environment In attempting to make up a list of variables that could best identify the sense of place in a residential environment, we have combined as many topics that came up in the ethnographic descriptions as possible into a common variable. This was done to limit the number of variables required to describe the particular sense of place in any residential environment. Following is the list of variables that have been selected:
A. Variables of Behavior:
Differences in norms and in life style between population groups
Characteristics of relations among the same population group ${ }^{3}$
Characteristics of relations with the other population group(s)
Use of public space and of public services

\section{B. Variables of Personal Feeling:}

Satisfaction, or aversion to the physical environment.

Feeling of belonging to similar buildings, to the street and to the neighborhood.

Feeling of belonging to a community

Feeling of security in public space.

\footnotetext{
${ }^{3}$ e.g. mutual consideration, mutual help, privacy, good relations, no contacts, conflicts
} 


\section{SENSE OF PLACE IDENTIFIED}

Following two tables summarize the sense of place thus identified in the Sapir and Yahalom housing developments:

Table 1: Variables of Behavior

\begin{tabular}{|l|l|l|}
\hline $\begin{array}{l}\text { Differences in norms } \\
\text { and in life style } \\
\text { between population } \\
\text { groups }\end{array}$ & $\begin{array}{l}\text { Pronounced differences in } \\
\text { norms of behavior and life } \\
\text { style of new and long time } \\
\text { population }\end{array}$ & $\begin{array}{l}\text { Pronounced differences in norms } \\
\text { of behavior and life style of new and } \\
\text { long time population }\end{array}$ \\
\hline $\begin{array}{l}\text { Characteristics of } \\
\text { relations among the } \\
\text { same population group }\end{array}$ & $\begin{array}{l}\text { New population: very little } \\
\text { contacts between them. } \\
\text { Long time population: } \\
\text { mainly based on family ties } \\
\text { and mutual help only }\end{array}$ & $\begin{array}{l}\text { New population: good relations, } \\
\text { consideration, joint leisure activities. } \\
\text { Long time population: good, based } \\
\text { on friendship, family ties and mutual } \\
\text { help }\end{array}$ \\
\hline $\begin{array}{l}\text { Characteristics of } \\
\text { relations with the other } \\
\text { population group(s) }\end{array}$ & $\begin{array}{l}\text { Tension and conflicts between } \\
\text { new and long time population }\end{array}$ & $\begin{array}{l}\text { correct relations between "them" and } \\
\text { "us", new and long time population }\end{array}$ \\
\hline $\begin{array}{l}\text { Use of public space } \\
\text { and of public services }\end{array}$ & $\begin{array}{l}\text { New population: avoid using } \\
\text { public space \& services if } \\
\text { possible } \\
\text { Long time population: use } \\
\text { public space \& services }\end{array}$ & $\begin{array}{l}\text { New population: use own public } \\
\text { space \& services } \\
\text { Old time population: use public } \\
\text { space\& services in old neighborhood }\end{array}$ \\
\hline
\end{tabular}

Table 2: Variables of Personal Feeling

\begin{tabular}{|l|l|l|}
\hline & \multicolumn{1}{|c|}{ Sapir } & \multicolumn{1}{|c|}{ Yahalom } \\
\hline $\begin{array}{l}\text { Satisfaction of or aversion to } \\
\text { the physical environment }\end{array}$ & $\begin{array}{l}\text { Lack of satisfaction, mainly by } \\
\text { new residents, but also by long } \\
\text { time residents }\end{array}$ & $\begin{array}{l}\text { Large degree of satisfaction, } \\
\text { both by new and by long time } \\
\text { residents }\end{array}$ \\
\hline $\begin{array}{l}\text { Feeling of belonging to similar } \\
\text { buildings, to the street \& the } \\
\text { neighborhood. }\end{array}$ & $\begin{array}{l}\text { New population: no sense of } \\
\text { belonging to residential envi- } \\
\text { ronment at all. } \\
\text { Long time residents: to old } \\
\text { building in their street only }\end{array}$ & $\begin{array}{l}\text { New population: sense of } \\
\text { belonging entire new housing } \\
\text { development } \\
\text { Long time population: to } \\
\text { entire old neighborhood }\end{array}$ \\
\hline $\begin{array}{l}\text { Feeling of belonging to a } \\
\text { community }\end{array}$ & $\begin{array}{l}\text { No feeling of belonging to a } \\
\text { community by either new or } \\
\text { old time population }\end{array}$ & $\begin{array}{l}\text { Feeling of belonging to a } \\
\text { community both by new and } \\
\text { by long time population }\end{array}$ \\
\hline $\begin{array}{l}\text { Feeling of security in public } \\
\text { space. }\end{array}$ & $\begin{array}{l}\text { New population: lack of } \\
\text { feeling of security } \\
\text { Long time population: fair } \\
\text { feeling of security }\end{array}$ & $\begin{array}{l}\text { Feeling of security both by } \\
\text { new and by long time popula- } \\
\text { tion }\end{array}$ \\
\hline
\end{tabular}




\section{DISCUSSION}

Sense of Place and the methodology of its identification: This study has endeavored to find a way of relating the moving in of a new population and the physical design of new housing developments in existing old neighborhoods with their sociological impact on the behavior and feeling of the populations involved. Identification of the sense of place as a multivariable indicator of behavior and personal feelings seems to be able to serve this purpose. By using the methodology of ethnographic analysis of spontaneous descriptions by residents interviewed, we seem to have obtained a good indication of the actual feeling of those residents, with regard both to behavioral aspects of the population groups involved and to the physical environment. Analyzing the results according to a set of predetermined variables should enable the making of meaningful comparisons between different residential environments.

Evaluation of the methodology by comparison of two housing developments: Differences in socio-economic status between the long time population and the new population were large, both in the Sapir and in the Yahalom housing developments. The sense of place was however found to be quite different in the two housing developments. The new housing development had a negative effect on the sense of place in the Sapir development and its adjacent old buildings, while having a clearly positive effect on the sense of place of residents of the Yahalom development and its adjacent old buildings. The Sapir housing development created a sense of tension and conflict between the new and the long time residents, whereas the Yahalom housing development created a very positive, though diffe-rent sense of place both for the new as well as for the long time population.

As could be concluded from the interviews, it was mainly the physical layout of the Sapir housing development that has had an undesirable effect on the sense of place. For instance, absence of any physical separation brought about frequent encounters between the new and the long time residents which the new residents didn't like, and which often caused the long time residents to feel offended. . As opposed to that, the physical layout of the Yahalom housing development created a favorable sense of place. The separating wall around the new buildings was described as providing a sense of security to its residents, and the public space formed created meeting places and a sense of belonging to a community. Similarly, the long time residents living in the adjacent old buildings enjoyed the separation between "us" and "them", between their "urban village" with their extended family, and the "strangers" living in the new buildings.

Potential use: Interviews conducted with residents have shown how planning and design decisions may affect the behavior and feeling of people. This preliminary study has indicated that a comparison between the sense of place of two similar housing developments in terms of size and make up of their population has enabled to draw some conclusions as to preferable physical layouts of future housing developments in existing old neighborhoods. Additional studies will be required to further develop identification of the sense of place. Once further developed, the methodology of identifying the sense of place in residential environments may eventually enable to anticipate the effects of social and physical 
planning ahead of time, thus avoiding physical layouts and other decisions that may negatively affect the sense of place in new housing developments.

\section{CONCLUSIONS}

We propose to use "sense of place" as a multivariate characterization of a residential environment that expresses the subjective feelings and patterns of behavior of its residents resulting from relations between groups of residents, relations within each group of residents and their attitude to the physical aspects of the residential environment.

A methodology of ethnographic analysis of the descriptions of the residential environment by its residents has been developed, which focuses on evaluating a number of predetermined variables that together define the sense of place of the residential environment.

Identification of the sense of place has been evaluated in comparing two new housing developments built in two old neighborhoods in the city of Ramat Gan. Results show significant differences in sense of place between the two residential environments that may be attributed to differences in their physical lay out.

Identification of the sense of place enables comparison between different residential environments with regard to the relations between social interaction and the physical environment, the conclusions of which could be used in planning new housing developments, particularly if located in old neighborhoods.

Since this study was of an initial exploratory nature, additional studies will be required to further develop identification of the sense of place as a methodology for evaluating and comparing residential environments, and to enable anticipation of the effects of social and physical planning on the resulting sense of place.

\section{References}

Billig, M., A. Churchman, 2003: Building walls of brick and breaching walls of separation. Environment \& Behavior 35 (2), 227-249.

Churchman, A. \& Rosenfeld, N., 1978: Guidelines for the design of residential environments: The precinct level. Haifa: Technion, Faculty of Architecture and Town Planning. (Hebrew).

Geertz, C., 1973: The Interpretation of Cultures. Basic Books, Inc.

Hallman, H.W., 1984: Neighborhoods, Their Place in Urban Life. Beverly Hills: Sage.

Isaacs, R., 2000: The urban picturesque, an esthetic experience of urban pedestrian places. Journal of Urban Design 5 (2), 145-148.

Jackson, J.B., 1994: A Sense of Place, a Sense of Time. (New Haven CT, Yale University Press.

Jiven, J. \& P.J. Larkham, 2003: Sense of place, authenticity and character, a commentary, Journal of Urban Design 8 (1), 67-81. 
Knopf, K.S., 1996: Urban tissue and the character of towns. Urban Design International 1 (3), 247-243

Rapoport, A., 1980-1981: Neighborhood homogeneity or heterogeneity. Architecture \& Behavior 1, 67-77.

Rapoport, A., 1997: The nature and the role of neighborhoods. Urban Design Studies 3, 93118. 